\title{
Interview with Northrop Frye
}

\author{
Francesco Guardiani
}

It is perhaps the idea of longevity that most often comes to mind in thinking of Northrop Frye. I am not referring, obviously, to the age of the man, who, although in his seventies, continues to write book after book with undiminished intellectual energy, but to the age of his theory of literature. After so many meteors that appeared and vanished in the sky of criticism in the last two or three decades, Frye's star remains brighter than ever. From the time of his seminal work on Blake (Fearful Symmetry, 1947) he has followed a well defined critical path, one which today, after countless essays, has become a wide and well-levelled highway, travelled by scores of students as well as by seasoned professors. A highway such as this is clearly marked in every map and therefore it might appear superfluous to retrace its route. But every cartographer of literary criticism has his own style and his own set of abbreviations, and perhaps only with the superimposition of several different maps is it possible to get one's bearings. It might be of some value, then, to open this interview by sketching a bricf outline of the Fryean highway: it will remind the reader of the general direction of his criticism and supply a context for the conversation that follows.

Terry Eagleton, one of the least sympathetic readers of Frye, once defined him as a "proto and post-structuralist" (Eagleton 1986, 123133). The prefix "proto" is there to remind us of a scientific approach to literary criticism noted especially in Anatomy of Criticism, whereas the "post" refers to a sort of "degraded romanticism" which Eagleton sees in the human desire for creativity which can only realize itself in the realm of Paradise. I think that these highly provocative remarks bear some elements of truth, something positive about Frye that even his staunchest critics are forced to acknowledge. Eagleton implicitly recognizes, in fact, what is most important in Frye's theory, namely his concept of literary structure.

Structure is, first of all, the idea one develops after reading a work of literature and asks oneself what its total meaning may be. It is, 
therefore, a perception of the work as a whole. Even this rather elementary concept of structure could be disputed by some "pre" or "post" structuralist critics since they appear to be interested more in "meaningful" segments of the text rather than in the total vision that it projects. In Italy, this totalizing concept of structure still meets some resistance, especially for those who cling to the "poesia c non poesia" dichotomy of Crocean memory, which assigns pre-eminence to particular passages of the text over the others. However, the fact is that this concept of structure has entered in the practice of criticism everywhere; if nothing else, it has become an easily recognizable critical term.

Frye, however, goes beyond this. His idea of structure surpasses the boundaries of the literary work and extends over literature itself, taken in its totality. The amplified concept of structure presupposes an "order of words," an internal framework integrating every work of literature, which is recognizable in the conventions, genres and clusters of archetypes within which literary creation finds expression. Such a framework is described in detail in Anatomy of Criticism. Here Frye is undoubtedly a "structuralist," in the sense that the enlarged concept of structure leads him to identify the series of categories that sustain the entire framework. But his type of structuralism is of a peculiar brand, certainly different from that of the French school-to which the term is more commonly associatedwhere there is a programmatic search for the "deep structures of narration" presenting the rigour and the coherence of scientific results.' Over the years, Frye has distanced himself even more than before from the "pre" and "post" structuralists who tend to focus their attention on smaller units of literary discourse: new criticism points to the ambiguity of the verbal texture, deconstruction insists on the unsubstantiality of language, always "delayed" in offering its meanings.

Frye has proceeded towards a definition of structure even ampler than the ones already formulated. It is one that takes into account the whole context in which literature expresses itself, one, that is, which encompasses all of the humanities. The unifying force in this bold and general vision of literature is mythology. Mythology is a factum of mankind that is the highest testimony of human capacity; it is with it and within it that man creates and gives shape to his 
own destiny. The purely creative activity of the arts carried on in this context is flanked by the other speculative activity of mankind, which is the pursuit of science. At the apex of Frye's vision we have therefore a double perspective concerning the main activity of the human intellectual; on one side energy is channelled toward the creative, on the other toward the descriptive. The universe of mythology is an all-encompassing entity, but it excludes the world of science because it merely tells what is there and not the human reality that we make: "I would even risk the suggestion that the physical sciences have never contributed anything to the mythopoeic worldpicture except through misunderstanding and misapplication. If that is true, then the moral is clearly that science is its own world-view, and should be distinguished from the mythical one" (The Stubborn Structure, 18-19). This statement indicates clearly the abyss which separates Frye from the French school of Structuralism, oriented toward a scientific understanding of all human experiences.

The world of the critic, then, has to focus on the world of creation, the world of myth, where the total vision of the human condition is represented. The function of the critic is to show the relevance of this world to society. In fact, the critic is the mediator between art and society, and this is why "the great bulk of criticism is teaching at all levels, from kindergarten to graduate school"(The Educated Imagination, 55). The work of the artist is the fulfillment of the creative energy of man in its purest form; nature, the "outside" world exists only because man is in it and gives it shape through artistic creation. The responsability of the critic, then, is precisely to show us the reality of the "inside" world which is the true world: "Reality is what we create and not what we contemplate" (The Stubborn Structure, 51).

In conclusion, Frye's vision of literature implies a vision of life in which man, because of his creative energy, is recognized as the only divinity able to give shape to the world. And if mythology gives us an assurance of being immersed in such a world, its human shape reminds us of its finite form and calls on our responsibility to recreate it. 
FRANCESCO GUARDIANI: The main thesis of Anatomy of Criticism was the establishment of a 'new science,' if I may use the expression, of literary criticism as an empirical, systematic and progressive discipline drawing directly from literature the necessary instruments of analysis. The new discipline should be free from the direct experience that one might have in reading literature and free from the dependence on other disciplines such as philosophy, psychoanalysis, history et cetera. In regard to the first point, what do you have to say to Harold Bloom protesting that "There are no texts. There are only ourselves"? (Salusinszky, 73). Do you think that criticism can be creative? In regard to the second point, I would like you to expand on what you have observed lately, when you said that criticism has not really evolved from its infancy, being "still bound up to ideology, and consequently much more concerned to develop the language of argument and thesis than really to embark on the empirical study of literature." (Salusinszky, 32). Are you less hopeful now, with respect to the establishment of a new criticism, than you were thirty years ago?

NORTHROP FRYE: I don't see that Bloom's remark is anything more than a boutade: it's a statement of pure solipsism, and while solipsism is always difficult to refute, it's also easy to ignore. I've rather lost interest in talking about the scientific nature of criticism, not because my views have changed, but because conceptions of science (more particularly social science, which is the context involved) are still too inflexible. But whenever critics disagree with each other the only effective disagreement is about the meaning of a text, and the text is always there to appeal to.

As there are now about fifteen schools to every one that there were in the nineteen-fifties, it is about fifteen times more true than it ever was that criticism is bound up with idcologies. Good work may be done within any critical school, but in the aggregate they form a self-enclosed interminable argument. What 1 feel now, however, is that the pluralistic tendency must work itself out to exhaustion before any real advance in criticism can occur.

FG: Literary criticism has been constantly sustained by the support of philosophy. Storms of scholars in the past studied Kant, Hegel 
and, at least in Italy, Croce in order to speak competently as literary critics. Today they study Nietzsche and Heidegger. 1. Do you think it is a healthy attitude? 2. Do you think it is necessary to contain the influence of philosophy to remain in the boundaries of literary criticism? 3. Where does philology fit in this concentration on theory? 4. How about the help that a critic can get from psychology? (I know that I am speaking to somcone who has meditated on hundreds of books of psychology, who has a particular penchant for Jung, who has recently written on Lacan ... . . ${ }^{2}$

NF: In my student days, the literary establishment was mainly philological and historical (the study of modern literatures in the 19th century grew up partly as a by-product of imperialistic ideology, which doesn't say that the study itself was wrong). A number of my seniors were reacting against this and stressing the relevance of philosophy, forming what was called a "history of ideas" approach. I belonged to a generation in which the relevance of psychology and anthropology was also becoming obvious. No sensible critic can question the relevance of these disciplines to the literature that borders on them: what I have consistently objected to is turning literary criticism into a specialized branch of philosophy or whatever.

FG: In a previous conversation, never recorded, you mentioned that your reading of Vico was an important and revealing expericnce. You felt that you "had been there before" having previously studied Blake and having been "inoculated," that was your word, by his works. What were the cycles of history that you found in Blake?

NF: Blake saw the revolutionary movements of his time in America and France as a repetition of the revolutionary movements in the Bible represented by the Exodus in the Old Testament and the Resurrection in the New. Both of these "betrayed" revolutions: The Exodus turned into Jewish legalism and the Resurrection into Christian authoritarianism. He saw the industrial movement of his time, including the slave trading in America, the Napoleonic wars, and the intellectual rationalizing of these things, as evidence that the revolution in his day also contained elements of his own reversal. Out of that he developed a cyclical view of history, 
symbolized as a periodic birth of "Ore," the revolutionary impulse, Orc being eventually martyred or aging into the opposite of himself. "The Mental Traveller" is one of several poems that describe this.

FG: Vico, like Blake, was interested in understanding the products of mankind, rather than its environment. But Vico, unlike Blake, had no problems in recognizing the presence of a divine power external to man. Who made the world of nature for Blake?

NF: Vico lived in a much more hysterical climate of opinion than Blake did, and he deliberately avoids all problems connected with sacred or Biblical history. But his axioms of verum factum, that man understands only what he has made, and that he has made history, obviously carries him far beyond this putting of history into sacred and profane compartements. As for Blake, he regards nature as either chaos or a human creation: "where man is not, nature is barren," he says, and in the imaginative or creative state all objects in nature are "men seen afar."

FG: Blake, you say, "is the first person in the modern world who understands that the older mythological construct had collapsed and that a new one had to be created" (Creation Recreation, 55). What is the sense of "creation" for him and how far is he fron Nietzsche?

NF: All creation for Blake is also recreation. What is recreated is the original creation before the fall, the fall being a power-struggle among "Eternals," human-titanic beings. Hence all creation today has a pre-existent model, and The Four Zoas ends: "How is it that all things are chang'd, even as in ancient time?" For him all energy is either creative or perverted and destructive: there is no "will to power" in him as in Nietzsche, where power is not identified with creativity.

FG: You made extensive use of the concept of typology ("a vision of history") in The Great Code, the Bible being the typological text par excellence. Yet the temporal distance that necessarily seem to associate the antitype to the type is disregarded by Blake as a fallacy. How do you reconcile his "ethernal Now" with typology? NF: Blake thinks of the climax of imaginative power as the collapsing of time into an "Ethernal Now," certainly. But he also realizes 
that man lives in history, and describes, among other things, a temporal sequence of seven ages symbolized by different names under which God has been worshipped, the last two being Jehovah and Jesus. Both Testaments of the Bible represent a past looking forward to a future: what Blake means by the "mental fight" of building a New Gerusalem is the turning of the future into the present, not waiting for some inevitable process to unroll itself.

FG: It is your view that there is something in Blake that makes him stand out of his own historical time. Harold Bloom said that reading Fearful Symmetry one never knows when Blake ends and Frye begins. I believe, with many others, that in fact your work as a critic, like Blake's writings, has a certain atemporal quality even though it is clearly rooted in our times. Have you ever thought about it?

NF: I think every creative effort springs out of its own time, and to the extent that it "springs" it rises above it. One cannot deal critically with any writer without taking both his relation to his own time and his relation to us into account. There must be elements in Dante that rises out of the thirteenth century or he would not still be a great poet to us; but if we ignored his thirteenth-century context we should simply be kidnapping him into our own cultural presuppositions. I felt that I could write about Blake only by entering his mind as completely as possible; but I think I kept his eighteenth-century context in mind too.

FG: Bloom has no problem in seeing literature, and literary criticism with it, as a narcissistic experience. Your idea is totally opposed to that, but narcissism seems to be very common among creative writers. Do you see some value in it? You clarify the difference, in Creation and Recreation, as well as in The Great Code, between two different kinds of faith: the one we think we believe in and the one that is the principle of our actions, which is rooted in our cultural identity. Do you see the possibility for literature to touch us on the deeper level of faith?

NF: Narcissism is the normal attitude that most writer, and probably all readers, begin with. It's essentially an immature attitude, and must be outgrown before any genuine distinction in creative or critical work can emerge. At a certain point you realize that that 
lovely face is in the water and that yours is in the air, at that point you stop seeing the reflection of yourself and start looking for fish. Similarly, there are two levels of reacting to literature. One can think of one's reading as an acquirement, as a body of cultivation one possesses: that's a stage of connoisscurship, where the moral nature is not touched. I think there are much profounder and more deeply committed ways of approaching literature, and that those would affect the personality, but most people who get to that stage do so unconsciously.

FG: In your theory, in general, and in your dealing with Canadian literature in particular, you have resisted the notion of the "global village," proposed by your good friend the late Marshall McLuhan. You said that the trend to unify and to conglomerate, which is so clear in politics and economics, is reversed in literature and culture. Yet more and more people in our day and age move from place to place, from courtry to country, from culture to culture; a good number of "Italians" I know here do not speak the language of their parents, some of them were born in Belgium, in Germany, in Switzerland, where their parents had settled before deciding to move to Canada. What is their cultural identity? Where is their "genetic identity" so important in your concept of faith. Moreover, the movement from culture to culture can be an intellectual journey of no less importance: your "Canadian" ideas are shared by readers in South America and in Japan, Derrida was born in Africa, educated in France and is now mostly appreciated in the U.S. Do you regard these cultural exchanges as ineffectual in defining cultural identity?

NF: McLuhan's global village was a conception developed quite explicitly in connection with the electronic media, and it's true that they impose a cultural conformity wherever they go. But there are also cultural cottage industries, like writing and painting and composing, that trend to decentralize society and form a kind of counter-environment. When I speak of being "rooted" in a culture l'm using a vegetable metaphor, and man, being an animal and mobile, can choose (or at least drift to, like a seed) the place where he will root. There are expatriate writers, but they're not necessarily rootless. They've simply gone somewhere else, and I should certainly agree that movements from one culture to another 
can be a deeply enriching experience. The essential thing is that one should write out of an imaginatively coherent environment, however one constructs it. By that last I mean that the coherent environment may not always be there: D.H. Lawrence roamed all over the world looking for his imaginative home, but it was that home he wrote from whether he was in Australia or Mexico or Sardinia. Coherent environment are always communicable and intelligible to other communities over the world, so that a writer may write in Nigeria or Colombia and get a Nobel Prize in Sweden.

FG: From the previous question I am tempted to expand into a much debated topic of today, the woman's cultural identity. Women's Studies is becoming increasingly relevant, in North America at least, as a 'new' subject in the humanities. Do you see significant innovations coming from it in the area of literary criticism?

NF: I find feminist criticism most interesting when it's an aspect of social history. The main principles of its specifically literary criticism are disappointing: they're quickly exhausted and don't sustain any novel or challenging interest. I'd much prefer to believe that it represented as new and important a dimension of sensibility as you suggest, but I haven't found it so, even if that is a statement only about me.

FG: In a recent interview Barbara Johnson expressed the very interesting notion that "women are all trained, to some extent, to be deconstructors ..." (Salusinszky, 169). It seems clear that there is a 'different' point of view out there, of enormous importance, that in the development of literary criticism has been completely neglected. How do you feel about it?

NF: The remark quoted is certainly interesting, but the word "trained" sounds a bit ominous: it suggests that deconstruction may be a twentieth-century form of needlework. Freud, though not highly regarded as a feminist writer, remarked that women were much quicker than men at picking up the subconscious elements in communication, and I suppose that that ability is related to deconstruction.

FG: On a theoretical level deconstruction criticism appears to be well grounded. You also gave credit to Derrida for having expanded 
the notion of 'delay' (Creation and Recreation, 19-20). But do you sec any problem coming from practical criticism? It appears to me that when the elusiveness becomes the rule one seems condemned to remain in the dark. There is also the problem of the infinite possibilities of 'other' meanings, of multiple 'differences, appearing in every line of a poem which, therefore, one might never finish reading. Do you see in the insistence on ambiguity and on texture (rather than on all-encompassing structures) a return to a type of criticism of the past? Do you see deconstruction as the most important post-structuralism trend?

NF: Yes, I think post-structural criticism is the "new" criticism of two generations ago refurbished with a more claborate theoretical framework. One is post-structural and the other pre-structural, but they both neglect the totality that the word "structure" is a metaphor for, and concentrate on texture. When I say totality I don't mean anything that can be finished and done with, but something that suggests a context or bigger totality beyond itself, in the way that the work of literature has the rest of litcrature for its context. I think it's only that sense of context that enables literary scholarship to make genuine advances.

In the Middle Ages the logic of syllogism promised new knowledge, but failed to provide any because the conclusion said only what the major premise told you already. So it remained simply a methodology for ensuring correct reasoning. I think the logic of supplement may be in much the same case: it's a methodology of discovering aspects of texture, but not a progressive way of learning about literature.

FG: Marxist critics do not like deconstruction for obvious reasons. They are closer to your position because you assign great relevance to the social function of criticism. Where is the point where you split from Marxism?

NF: I split from Marxism at the same point where I split from everything in criticism that finds the essential explanations of literary phenomena in something outside literature. I seldom object to the explanation itself, only to the assumption that it's not just one of many, but the explanation that makes all others unreal.

FG: There is a new tendency today to see Marxism not as an ideol- 
ogy, but as a method to assess, verify, and possibly condemn all ideologies. Do you see this as a healthy trend?

NF: The tendency you speak of is a return to the original Marxist conception that it was the one structure of knowledge that had no ideology, ideology being only what bourgeoisie and counterrevolutionaries developed to avoid the challenge of the revolution. Whenever Marxism came to political power, however, it turned into one more defensive ideology. Marxism has always insisted on the inseparability of its theory and its practice, but it seems to me that an inconsistent Marxism, pure theory with no reference to what Marxism actually does to culture when it gets the chance to do it, would be the healthiest possible form of it.

FG: The social function of the critic is that of bringing people close to the arts, to open the access to a higher level of humanity. Yet the prospect may appear rather confusing if we consider that there are artists, immersed in the arts, whom you do not hesitate to call "ideological fat-heads" (Yeats, Pound and Lawrence, for instance). Should the critic, then, separate the poetry of an artist from his ideology? Is this possible to do without misrepresenting the artist?

NF: I once wrote a book on Eliot in which I began with two chapters on him as a critic. The first chapter dealt with his polemical and ideological criticism and treated it as part of a temporary fashion; the second chapter dealt with his genuine literary criticism, which has been permanently influential. I don't think I misrepresented Eliot, because I included both aspects of him, but it seemed to me that the two aspects fall apart like chalk and cheese. I did this mainly as an experiment for myself, trying to see if a writer's genuine work (as I saw it) could be separated from what looked to me just anxiety-junk. I think the separation is possible, though I'm aware of the easy objections to saying so. I know, for instance, that my own anxicty-junk would get into the act, but other critics could take care of that. Ezra Pound was a great poet and a nut: perhaps some great poets have to be nuts, but great poetry and nuttiness will always be different things, and it's part of a critic's job to see them as different.

FG: Your concern about the social value of literature has led you to work on an endless number of committees, both here and in the 
U.S., for the review of school curricula from elementary school to university, not to mention your work as an advocate of the unlearneds (no critic that I know has ever had the inspiration, or the courage, to produce something that comes close to that little masterpiece that is The Educated Imagination); you have also worked as editor of textbooks, and have always been available to lecture all over the world. Yet you never institutionalized your theorics and concerns with a school. Why?

NF: I suppose the short answer is that I now know enough about institutions not to want to become an institution. My experience with students, more particularly undergraduates, has given me an immense respect for non-specialized public opinion and I should want my influence to be a pervasive force that would help to set other people a little freer to do what they wanted to do in their own way. Some of them may turn antagonistic to me: that's their way of being influenced. But my' influence is one thing, and I hope a good thing: discipleship, with its routine of the did-hereally-say-this-or-that, scems to be tedious, not to say sinister.

\section{University of Toronto}

\section{NOTES}

1 The differences between Frye's structuralism and that of the French School are clearly described by Paul Ricocur in "Anatomy' of Criticism or the Order of Paradigms."

2 For a detailed and complete list of Frye's works, including his writings on psychology (Freud, Jung, Bachelard, Lacan), see the voluminous updated bibliography compiled by Robert Denham.

\section{WORKS CITED}

DENHAM, Robert D. Northrop Frye. An Annotated Bibliography of Primary and Secondary Sources. Toronto-Buffalo-London: University of Toronto Press, 1987.

EAGLETON, Terry. "L'idealismo nella critica americana," L'ombra d'Argo 3 (1986), ก. 7-8: 123-133. The arlicle originally appeared, in English, in the New Lefi Review (1981), n. 127: 53-65.

FRYE, Northrop. Anatomy of Criticism. Princeton NJ: Princeton Universily Press, 1957. . Creation and Recreation. Toronto-IBuffalo-London: University of Toronto Press, 1980. 
The Educated Imagination. Toronto: CBC Publications, 1963.

. The Great Code. New York: Harcourt Brace Jovanovich, 1982.

Fearful Symmetry. Princeton NJ: Princeton University Press, 1947.

. The Stubborn Structure. London: Methuen \& Co., 1970

RICOEUR, Paul. "Anatomy of Criticism or the Order of Paradigms," in Essays in Honour of Northrop Frye, Eleanor Cook et al. eds. Toronto-Buffalo-London: University of Toronto Press, 1983: 1-13

SALUSINSZKY, Imre. Criticism in Society. Interviews with J. Derrida, N. Frye, H. Bloom, G. Hartman, F. Kermode, E. Said, B. Johnson, F. Lentricchia, J.H. Miller. New York-London: Methuen, 1987. 